LA- $-9437-M S$

DE82 019492

\title{
Radiation Effects on Samarium-Cobalt Permanent Magnets
}

R. D. Brown

E. D. Bush, Jr.

W. T. Hunter

Ther Neis report was orepareas an avernment nor any agency thereot, nor any of their emoloveres, makcs any werranty. express or implied, of assumes any legal liability of resontsibilitivy for the accuracy.

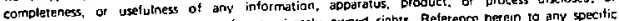

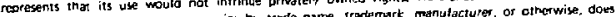

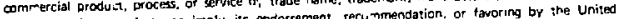

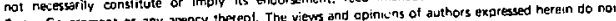

States Government or any apency her Un. The Sises Government or any xhency theseof. 
RADIATION EFFECTS

ON SAMARIUM-COBALT PERMANENT MAGNETS

by

R. D. Brown, E. D. Bush, Jr., and W. T. Hunter

\begin{abstract}
With the recent advances in rare-earth-cobalt (REC) permanent magnet technology, new applications are being implemented that were previously not feasible. One such application is the use of permanent magnetic lenses for accelerator and beam transport systems. In many of these areas the magnetic transport systems are subjected to high radiation levels. Consequently, there is considerable interest in the United States and abroad in the possible changes in the magnetic field when subjected to radiatior. This is a description of our approach in performing the fleld measurements before and after irradiating samples of samarium-cobalt permanent magnets.
\end{abstract}

I. METHOD OF MEASUREMENT

While measurements of the magnetic fields seem rather simple, there are several constraints that must be considered in this particular exercise. Techniques using flux coils, Hall effect gaussmeters, NMR gaussmeters, and rotating coll gaussmeters were considered in light of the sample size and handling limitations. Relatively small samples were required since REC permanent magnets are limited to relatively small sizes by the present technology. The technique selected had to be Immune to radiation from the exposed samples. Reproductbility of the sample location, magnitude of the output signal, and ease of performing the measurements of the Irradiated 
samples were also major considerations. We chose to rotate cylindrical REC permanent magnet samples magnetized across the diameter (Fig. 1) in a laminated Iron return yoke. Coils around the yoke provide a large, easily measured voltage output signal. The device is essentially a small, simple generator.

\section{APPARATUS}

The sample is mounted in a threaded aluminum ce11, Fig. 2. Aluminum was selected for the cell material to minimize the residual radiation. The sample cell is attached to a threaded spindle on the nonmagnetic stainless steel flywheel. A 1/20-HP, 3600-RPM, hysteresis synchronous motor rotates the sample within the core. Both the motor and core assembly are doweled to the aluminum base plate for positive location. Sample cells are easily changed through the open aperture in the core assembly using a $0.9-m$ long steel rod. The test apparatus is shown in Fig. 3.

\section{SAMPLES}

The two materials Investigated supplied by Hitachi Magnetics Corp. were Hicorex 9OB (Co5Sm) and Hicorex 96B (5:1 compound with Pr subst1tuted for 1/3 of the $\mathrm{Sm}$ ). Both materials were fully magnetized and stabilized to $100^{\circ} \mathrm{C}$.

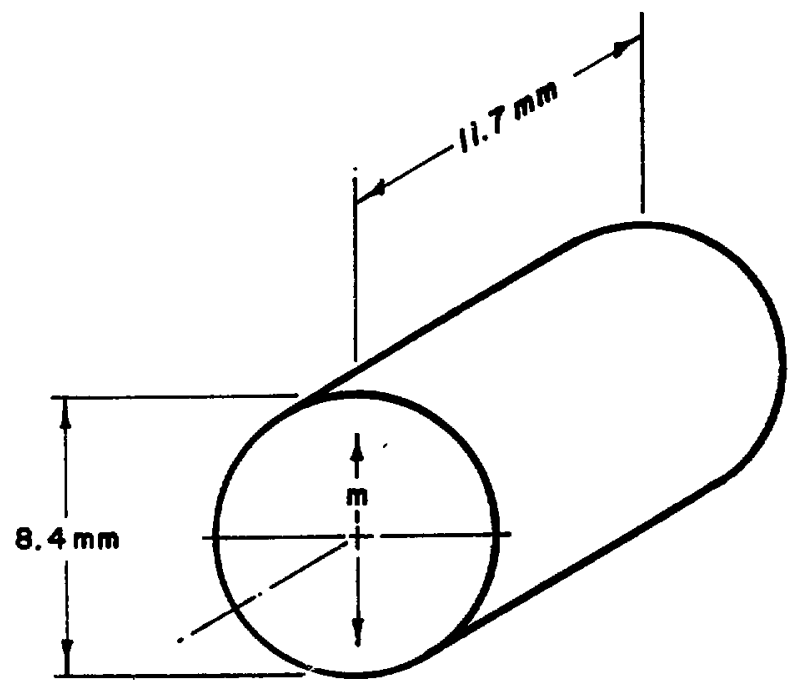

F18. 1

REC Permanent Magnet Sample Configuration. 


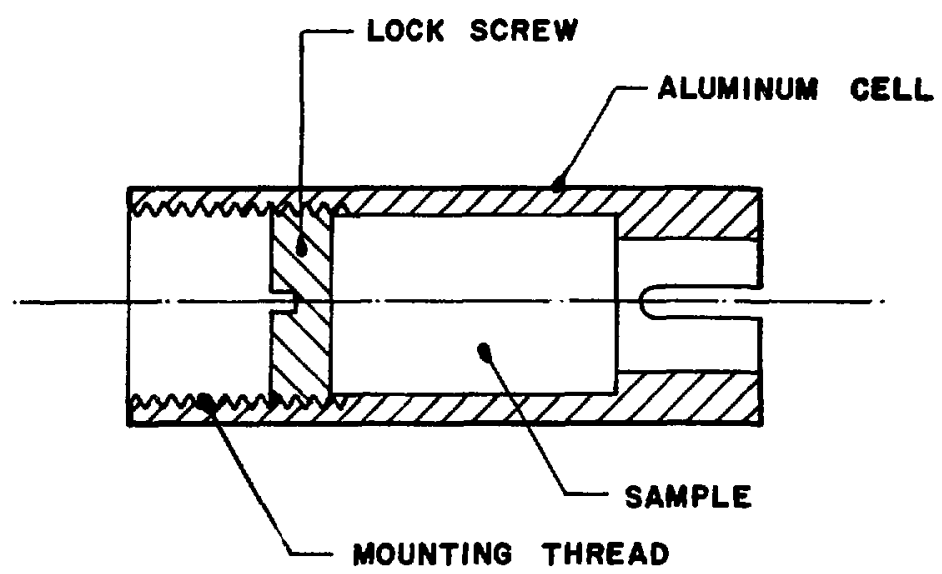

Fig. 2

Sample Holder.

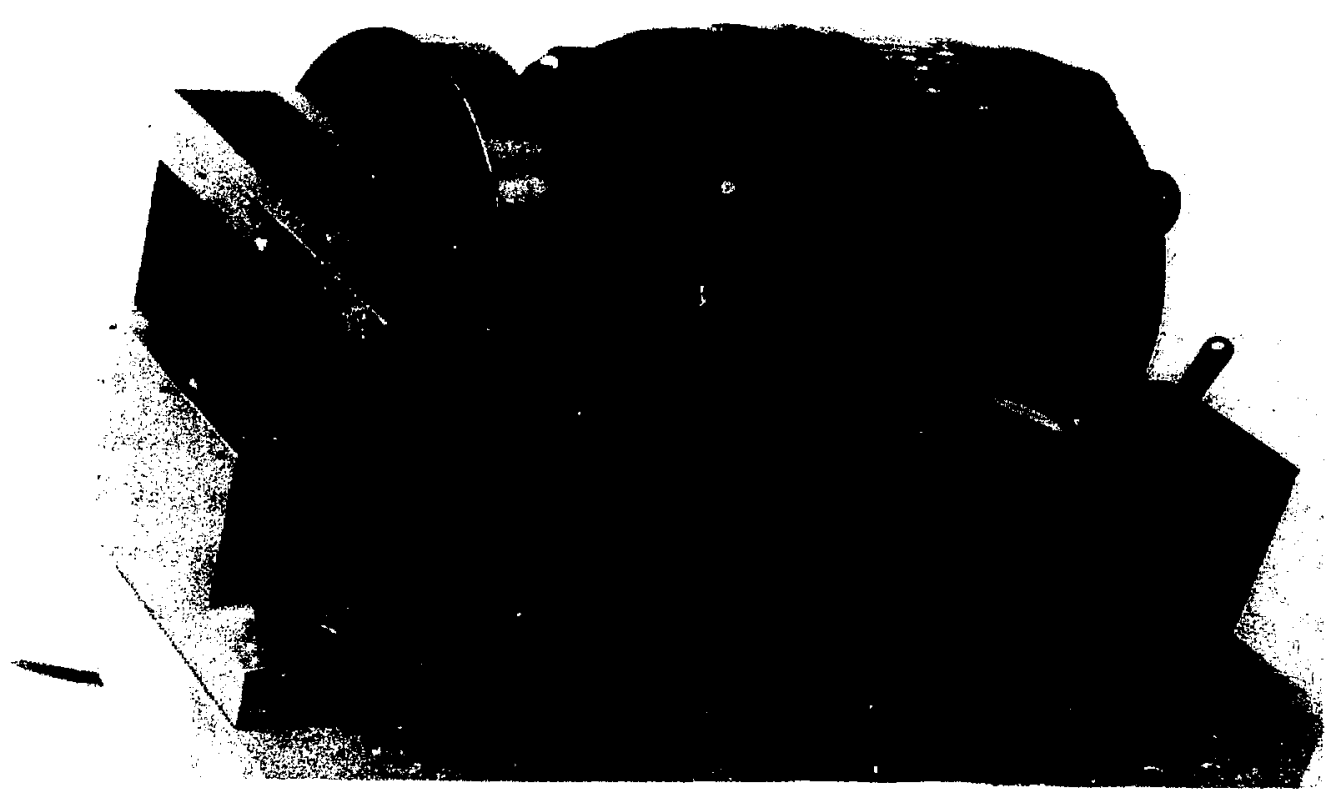

F.tg. 3

Permanent Magnet Fleld Test Apparatus.

The intrinsic and normal demagnetization curves for $90 \mathrm{~B}$ and $96 \mathrm{~B}$ are shom 10 F18. 4. FIve samples of each of the two naterials were Investigated. 


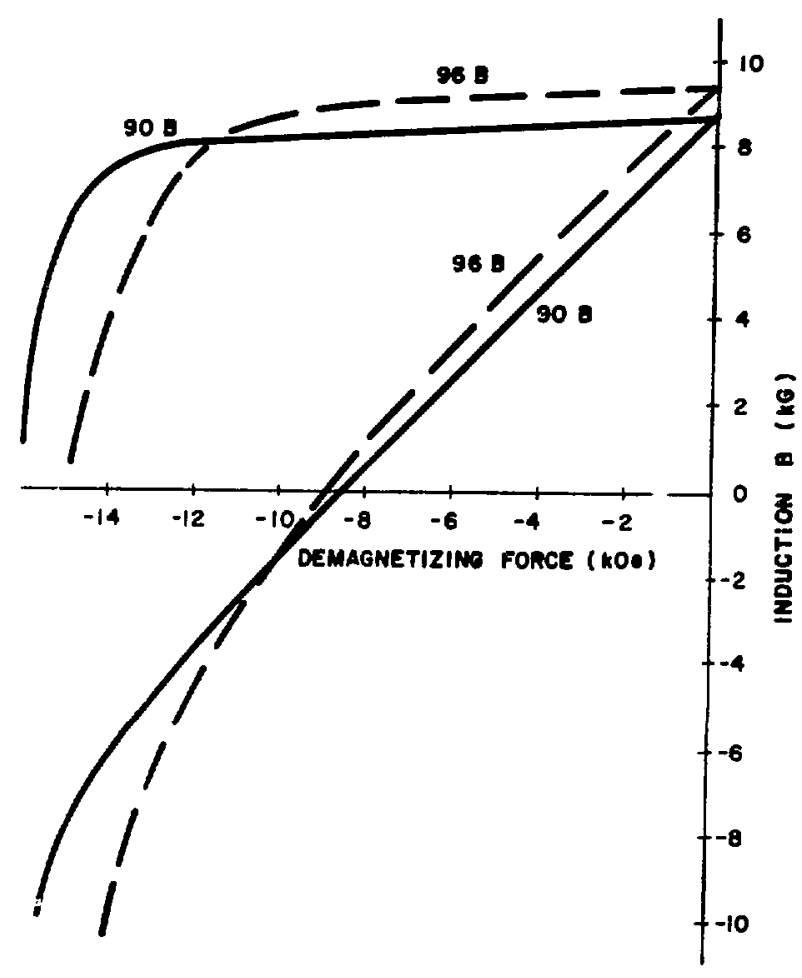

F1g. 4

Intrinsic and Normal Demagnetization Curves.

\section{IRRADIATION PROCEDURES}

Magnet samples were Irradiated at the LAMPF radiation effects facility, which provides access to spallation neutrons produced by the interaction of the LAMPF $800-\mathrm{MeV}$ proton beam with various 1sotope production targets and the LAMPF beam stop. Nickel and cobalt activation folls were attached to each group of samples. Gamma spectroscopy on the activated folls allowed determination of the neutron fluence vs energy as shown in Fig. 5. The curve shown presents the integral neutron fluence; that 1s, for any energy on the abcissa, the ordinate gives the total number of neutrons per square centimeter having energles greater than or equal to this energy. The shape of the spectrum was similar for the three ${ }_{15}$ roups of magnets 17 rradiated, while the fluences (for $\mathrm{E}>0.1 \mathrm{MeV}$ ) were $1 \times 10^{15} \mathrm{n} / \mathrm{cm}^{2}, 2.5 \times 10^{17} \mathrm{n} / \mathrm{cm}^{2}$, and $1.1 \times$ $10^{18} \mathrm{n} / \mathrm{cm}^{2}$. Temperatures near the magnet samples (as weasured by thermocouples) did not exceed $140^{\circ} \mathrm{C}$ at maximun proton bean current. 


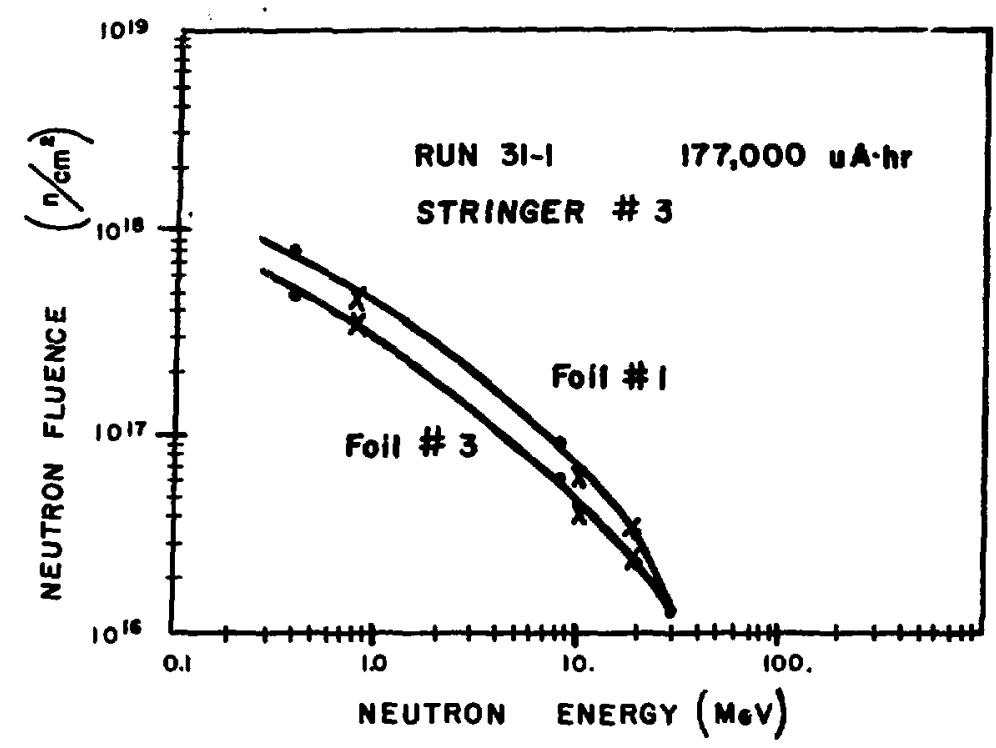

FIg. 5

Neutron Fluence vs Energy.

V. MEASUREMENTS

Voltage output measurements made wth a $31 / 2$-digit Fluke multineter both before and after irradiation are shown in Table $I$.

TABLE I

Vo1tage Output Measurements

\begin{tabular}{|c|c|c|c|c|c|c|}
\hline Fateriel & $\begin{array}{l}\text { Sump } 10 \\
\text { Mulerer }\end{array}$ & $\begin{array}{c}\begin{array}{c}\text { Defore } \\
\text { trredfintion } \\
(v)\end{array} \\
\end{array}$ & $\begin{array}{c}\begin{array}{c}\text { After } \\
\text { trrediation } \\
\text { (V) }\end{array} \\
\end{array}$ & 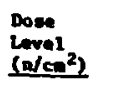 & $\begin{array}{c}\begin{array}{c}\text { Contect } \\
\text { Metivation } \\
\text { (u/hr) }\end{array} \\
\end{array}$ & $\operatorname{lt}_{(x)}$ \\
\hline \multirow[t]{5}{*}{ Hicorex 901} & $90 c 2045-1$ & 3.10 & 3.18 & $1.0 \times 10^{15}$ & 0.050 & - \\
\hline & -2 & 3.21 & 3.19 & $2.5 \times 10^{23}$ & 6.0 & 180 \\
\hline & -3 & 3.20 & 3.17 & $2.5 \times 10^{17}$ & 4.0 & 120 \\
\hline & -4 & 3.10 & 3.08 & $1.1 \times 10^{10}$ & 20.0 & 160 \\
\hline & -5 & 3.19 & 3.13 & $1.1=10^{10}$ & 20.0 & 100 \\
\hline \multirow[t]{5}{*}{ HLCoren 96: } & $96 c 2045-1$ & 3.18 & 3.18 & $1.0 \times 10^{15}$ & 0.050 & - \\
\hline & -2 & 3.17 & 3.16 & $2.5 \times 10^{27}$ & 4.0 & 15 \\
\hline & -3 & 3.20 & 3.19 & $2.5 \times 10^{27}$ & 4.0 & 15 \\
\hline & -4 & 3.19 & 3.15 & $1.1=10^{10}$ & 20.0 & 160 \\
\hline & -5 & 3.17 & 3.10 & $1.2 \times 10^{10}$ & 20.0 & 160 \\
\hline
\end{tabular}


V. CONCLUSIONS

The apparatus provided large voltage output signals and the sample handling was convenient.

While the loss in magnetic field was quite small ( $2 \%)$ it can probably be attributed to the fact that the samples were stabilized to $100^{\circ} \mathrm{C}$ but reached $140^{\circ} \mathrm{C}$ during the irradiation.

Hicorex $96 \mathrm{~B}$ would be expected to exhibit greater degradation because of its lower coercivity.

Future studies should include higher dose levels and samples should be stabilized to higher temperatures in order to isolate the cause of fleld degradation.

ACKNOWLEDGEMENTS

Although this was a rather simple activity it could not have been accomplished without the unique capabilities of LAMPF. State-of-the-art magnet samples were provided by F. G. Jones of Hitachi Magnetics Corp. E. J. Schneider provided valuable assistance in the design of the measuring equipment. 